$\begin{array}{lll} & \text { International Journal of Educational Studies in Mathematics } \\ \text { WWw.ijesim.com } & \text { ISSN: 2148-5984 }\end{array}$

\title{
Mathematics Learning and Teaching in Japanese Preschool: Providing Appropriate Foundations for an Elementary Schooler's Mathematics Learning
}

\section{Tomomi Sakakibara ${ }^{1}$}

${ }^{1}$ Tokyo Gakugei University

\section{ABSTRACT}

\begin{abstract}
Increasingly, it has become recognized that young children's mathematical knowledge is fundamental to their mathematics learning at school. Consistent with this claim, the mathematical knowledge of at-risk students (e.g., students from low-income families) is lower than that of those without risk, even at school entry. Similarly, Asian children have been shown to perform better at mathematics than their counterparts in many other countries, both at school and preschool level. This suggests that Asian children are better prepared for mathematics when entering schools than children in other countries. Children's mathematical learning at school benefits largely from appropriate pre-school education. This article proposes an alternative and potentially effective way to support young children's mathematical learning without relying on systematic teaching, by introducing Japanese preschool math activities as an example. The studies indicate that Japanese preschool teachers effectively facilitate young children's mathematics learning by frequently embedding mathematics in everyday activities. I consider that, for embedded mathematical activities to function effectively, a teacher must be sensitive to the children's current state of mathematical development. In addition, a teacher needs to be flexible in embedding appropriate levels of mathematics in response to children's spontaneous mathematical interests in a variety of activities.
\end{abstract}

Keywords:

Young children, mathematical activity, teachers, preschool education

(C) 2014 IJESIM. All rights reserved

Article History:

Received 21.02.2014 Received in revised form 05.04.2014 Accepted 08.05.2014 Available online 01.06.2014

\section{Introduction}

Cross-cultural differences in mathematical achievement have been widely acknowledged. In general, elementary school children in Asian countries outperform their counterparts in the US and many other countries. Stevenson, Lee, \& Stigler (1986) compared the mathematical performance of $5^{\text {th }}$ graders from the United States, China, and Japan. The highest average score of American classroom was below that of the Japanese classroom with the lowest average score. Their data also showed that, from a total of 720 children, a single US child ranked among the top 100, while 67 US children ranked among the bottom 100. More recent studies have revealed similar tendencies. TIMSS 2011 (Trends in International Mathematics and Science Study) compared the mathematical achievement of $4^{\text {th }}$ graders in 52 countries and regions. The top five countries in which high average scores were attained were Asian countries, namely Singapore, Korea, Hong Kong, Chinese Taipei and Japan (Mullis, Martin, Foy \& Arora, 2012).

${ }^{1}$ Corresponding author's address: Tomomi Sakakibara, Center for Research in International Education, Tokyo Gakugei University, 4-1-1 Nukuikitamachi Koganei-shi, Tokyo, 1848501, Japan.

Telephone: $+81-42-329-7724$

e-mail: tomo1120@u-gakugei.ac.jp

http://dx.doi.org/10.17278/ijesim.2014.01.002 
The superior mathematics performance of Asian elementary school children has been attributed to differences in mathematics teaching and learning at school, such as teaching styles in mathematics classrooms (Perry, Vander Stoep \& Yu, 1993; Stigler \& Hiebert, 1999), the use of proper textbooks (Mayer, Valerie \& Tajika, 1995), and time spent at mathematics learning (Stevenson et al., 1986). Attitudes towards children's achievement also differ between Western and Asian cultures. In particular, Japanese parents rated "effort" as important for children's successful performance in school, whereas American parents also emphasized "ability" (Stevenson \& Stigler, 1992).

These differences in mathematics classroom environments produce direct and indirect effects on children's mathematical achievement. However, studies with younger children indicated that cross-cultural differences in mathematical performance exist prior to elementary school entry. When entering elementary school, it appears that Asian children are better prepared for mathematical learning than their Western contemporaries. Ginsburg, Choi, Lopez, Netley, \& Chi (1997) examined the basic mathematical thinkingof four-year-old children from five different countries, including Japan and the US. Simulating a birthday party, they assigned ten tasks to individual children; nine informal math knowledge tasks and one digit span memory task. Overall, children from Asian countries (China, Japan, and Korea) performed significantly better than children from the US and Columbia. Similar findings were reported by Stevenson et al. (1986). They examined the basic mathematical concepts and operation of children in the US, China and Japan. In each country, 288 5-year-old children from 24 kindergarten classrooms were assessed. Young children from Japan scored higher than those from China and the US. No difference in mathematical competence was found between the Chinese and US children.

Prior to schooling, children acquire nascent mathematical skills and understanding in their everyday lives by participating in a variety of mathematical activities provided by their culture. Recent studies have confirmed that early mathematical knowledge provides a firm foundation for later mathematical learning at school (e.g., Jordan, Kaplan, Ramineni, \& Locuniak, 2009). Duncan et al. (2007) examined the links between school readiness and later school achievement, using six longitudinal studies of children aged 5 to 14 years. They found that children's school-entry mathematical skills predict later math achievement, even when cognitive factors, socioemotional factors, and family background were controlled. Similarly, Krajewski \& Schneider (2009) conducted a four- year longitudinal study on children from kindergarten to Grade 4 . They found that mathematically low-performing children in Grade 4 had performed poorly in their pre-school years, in tasks such as quantity-number competences, number naming speed, and basic arithmetic fact retrieval. The importance of young children's mathematical knowledge has also been emphasized in national studies of socioeconomical difference in mathematical performances. In these studies, young children, as well as elementary-level children, from low-income families scored lower than their middle-income counterparts (Jordan \& Levine, 2009). At school entry, children from low-income families appear less prepared for learning the mathematics curriculum than those from middle-income families. Their mathematical disadvantage at school entry persists into the middle grade and beyond. To better support children's mathematics learning at school, appropriate pre-school education seems imperative.

How should we effectively facilitate young children's mathematical learning? In China, many preschools provide formal mathematics instruction, which has proven successful at facilitating mathematics learning by young Chinese children (Ginsburg, et al., 1997). Teaching mathematics systematically is one way to facilitate mathematical learning, since it effectively provides young children with the mathematical knowledge required for later school learning.

Interestingly, in other Asian countries such as Japan, teaching academic subjects to preschool children is considered unfavorable (Ministry of Education, Culture, Sports, Science and Technology, 2008). Rather, Japanese preschool teachers and parents emphasize children's social development, such as sympathy, empathy and concern for others. These are regarded as essential elements of preschool learning. When questioned on the relevance of preschools in society, only $2 \%$ of Japanese parents and teachers selected academic goals among their top three reasons. By contrast, more than half of US and Chinese parents selected this option (51\% and 67\%, respectively; Tobin, Wu, \& Davidson, 1989). Similarly, in our interview study, many Japanese preschool teachers reported an unwillingness to teach mathematics to their children (Sakakibara \& Hatano, 2004). 
In the following sections, an alternative approach to supporting young children's mathematical learning is presented. By means of an observational study I have conducted, I discuss how Japanese preschool teachers support such learning without relying on systematic teaching (Sakakibara, 2006). I then discuss the factors required for effective functioning of this support.

\section{Classroom Observation of Japanese preschool activities}

Sakakibara (2006) conducted classroom observations of 3- and 4-year-olds at seven private preschools over a one-year period. All seven preschools that participated were co-ed with an average enrollment of 207 children. At the beginning of the study, the per-classroom averages of three- and four-year-olds were 24 and 26, respectively (respective ranges 23-34 and 24-29). One or two teachers were present in all classrooms, and an assistant teacher presented occasionally in some classrooms.

The study comprised 70 classroom observations, five observations at each of 14 classrooms (two classrooms per preschool). For each observation, two trained observers visited the target classroom and observed activities using field notes and two video cameras. Mathematical behaviors of children and teachers, in addition to general activity shifts, were recorded in the field notes. Observations were conducted for two hours (9:30 to 11:30 am), until the children began to prepare for lunch or until an activity in progress was completed.

Collected data were analyzed as follows. First, the details of the teachers' and children's mathematical behaviors, as well as the general shifts in activities, were added to the field notes from the corresponding videotapes. From the supplemented field notes, activities that differed according to the teachers' purpose were identified for the70 classroom observations. For the purpose of this study, I classified each activity as a teacher-initiated (TI) activity or children's free-play, and excluded the latter group. In the next step, TI activities were identified as mathematical or non-mathematical. An activity was considered mathematical if more than one instance of mathematical behavior by the children or teachers was observed. The areas of mathematics included in the analysis were numbers (e.g., counting), arithmetic (e.g., addition and subtraction), space and geometry (e.g., naming or recognizing shapes), measurement (e.g., comparing magnitudes), and patterns (e.g., making or recognizing patterns). Any activity involving at least one of these five mathematical areas was regarded as a "mathematical activity." Mathematical activities were then identified according to whether mathematics was the focus of the activity (focal activity) or whether it was embedded in the activity (embedded activity). Finally, the types of activities were identified. The observations included 44 types of TI activities, including 27 structured activities and 17 routine activities. Structured activities were those planned and selected by the teachers, while routine activities were conducted repeatedly throughout the year under teacher guidance. The different types of TI activities are displayed in Table 1.

Table 1.Types of Observed Activities and Examples of Mathematical Behaviors (Sakakibara, 2006)

\begin{tabular}{|c|c|c|}
\hline Types of activities & Content of activities & Examples of math behaviors \\
\hline \multicolumn{3}{|l|}{ I. Set-Up Activities } \\
\hline Singing & Singing songs & $\begin{array}{l}\text { Singing number songs; Expressing numbers, sizes or } \\
\text { shapes with their bodies }\end{array}$ \\
\hline Musical instruments & Practicing musical instruments; Listening to music & - \\
\hline Arts and crafts & Creating art projects & Confirming numbers, sizes, or shapes of the materials \\
\hline $\begin{array}{l}\text { Preparing for arts and } \\
\text { crafts }\end{array}$ & Preparing materials for creating art projects & $\begin{array}{l}\text { Adjusting the number of children in one group; Confirming } \\
\text { the order of the children as they finished preparing }\end{array}$ \\
\hline $\begin{array}{l}\text { Playing with self-made art } \\
\text { projects }\end{array}$ & Playing with self-made arts and crafts objects & $\begin{array}{l}\text { Limiting the number of children who enter the bathtub } \\
\text { made of corrugated cardboard }\end{array}$ \\
\hline Exercising & Moving bodies without music & Counting out numbers \\
\hline Dancing & Moving bodies with music & $\begin{array}{l}\text { Making groups of a certain number of children; Counting } \\
\text { out numbers }\end{array}$ \\
\hline Bathing pool & Swimming & $\begin{array}{l}\text { Confirming the number of pool toys brought into the } \\
\text { swimming pool }\end{array}$ \\
\hline Animal Care & Feeding and observing animals & Counting animals; Comparing the sizes of animals \\
\hline
\end{tabular}


Cultivation

Storytelling

Reading picture books

Japanese

Mathematics

English

Geography

Adjusting writing pressure

Games

Pretend play

Teacher's performance

Birthday celebration

Practicing performances

Visiting other classrooms

Measuring heights and weights

Evacuation drill

Instruction for facility use Learning how to use the preschool facility

Practicing standing in lines Practicing standing in lines observing

Reading of storybooks by teachers

Reading picture books

Learning Japanese

Learning mathematics

Learning English

Learning Geography (e.g., names of cities)

the pen when writing certain rules

Playing make-believe equipment (e.g., spinning tops) month it is recital
Nurturing plants by seeding, watering, and Counting holes to bury seeds; Comparing amount of growth

Paying attention to the shapes of the illustrations; Counting numbers along with the lines

Reading picture books about matching numbers

Reading proverbs or words that include numbers

Counting the beads of an abacus; Giving the names of shapes

Counting numbers in English; Saying one's age in English

Drawing lines to adjust pressure a child puts on Connecting numerals with lines counting 1,2

Playing games that require children to follow Using dice; Counting traditional Japanese playing cards

Counting the money left or the number of goods purchased in pretend play

Watching teachers demonstrate the use of play -

Celebrating children whose birthday or birth Asking age; Counting candles as they are blown out

Practicing performances such as dramas for a Confirming the order of appearance; Giving a signal with numbers

Observing the activities of other classrooms

$-$

II. Routine Activities

Attendance note Putting a sticker in children's attendance book

Taking attendance

Taking attendance of children

Class gathering

Greetings

by the teachers

All the children are greeted led by a teacher / children on duty

Introducing children on Teacher interviews children on duty

duty

Date Confirmation

All the children confirm the day's date, led by teachers children on duty

Matching the numbers marked on stilts and their storages Comparing the heights of children in line; Teachers write the number of one's place in line on a cap

Checking future activity Teachers confirm future activity schedules (date, Teachers explain the beginning of playtime using a clock schedules contents) with the children

Discussion about activity Planning an activity initiated by teachers content

Thinking back on activities Thinking back on activities initiated by teachers

Deciding what types of shops will be part of pretend play by majority vote

Receiving letters or Teachers distribute letters or materials to children materials for parents during classroom gathering

Counting the number of characters in a play

Receiving awards

Receiving award from teachers

Teachers talk about living Teachers talk about the weather, clothes, or living habits habits

Health-care habits

Going to the bathroom, washing hands, drinking Having a rubdown with a dry towel while counting out water, or having a rubdown with a dry towel, as numbers instructed by teachers

Clean-up

All the children clean up the toys, as instructed by Placing blocks in containers to match the container shape teachers

Prayer / Meditation

Saying one's prayers / Practicing meditation

Changing clothes

Changing clothes (e.g., gym suit or bathing suit) Putting on a cap when three whistles are given or putting on / taking off cap

Changing location Moving to another location, as instructed by Counting out numbers when running to change location teachers 


\section{How Frequently Were Mathematical Activities Practiced in Japanese Preschools?}

The results showed that, in Japanese preschools, mathematics was observed fairly frequently in 367 out of 921 observed TI activities (40\%). Almost all of the mathematical activities - 358 out of 367 (98\%)-were embedded activities. Focal math activities were rare, comprising just 9 of the 367 activities (2\%). Among the five areas of mathematics, numbers were observed most frequently (316 activities; $86 \%$ ). Patterns were rarely observed-occurring in only 3 activities and constituting a mere $1 \%$ of all math activities.

\section{In Which Preschool Activities Were Mathematics Observed?}

Of the 367 total math activities, 213 were structured activities (58\%) and 154 were routine activities (42\%).Table 2 shows the number of mathematical activities observed for the different activities.

Mathematics was involved in 213 (52\%) of the 407 structured activities, being most frequently observed in singing (43 activities), arts and crafts (36 activities), and exercising (22 activities). Within an activity, arts and crafts embodied the most frequent mathematical behavior ( $84 \%$ of all arts and crafts activities), followed by exercising (59\%), and dancing (53\%). Of the five areas of mathematics, number activities such as counting were most frequent (observed in 180 activities; $85 \%$ of all structured mathematical activities). Arithmetic and patterns were the least frequent areas in structured activities, included in only $8 \%$ and $1 \%$ of structured math activities, respectively.

Mathematics was involved in 154 of 514 routine activities (30\%). Math-related activities were observed most frequently in taking attendance ( 44 activities), followed by class gathering ( 25 activities), and clean-up (19 activities). Within an activity, date confirmation and attendance-taking embodied the most frequent mathematical behavior (100\% and $83 \%$ of observed activities, respectively). Among the mathematics areas, activities involving numbers were most frequent (136 activities, representing $88 \%$ of all routine mathematical activities). No activities involving patterns were observed during routine activities.

Table 2.Number of Mathematical Activities Observed for Different Types of Activities (Sakakibara, 2006)

$\begin{array}{lcccc}\text { Types of activities } & \begin{array}{c}\text { Total \# of } \\ \text { activity }\end{array} & \begin{array}{c}\text { Math } \\ \text { activity }\end{array} & \text { Numbers } & \text { Areas of mathematics } \\ \text { Arithmetic } & \begin{array}{c}\text { Space \& } \\ \text { Geometry }\end{array}\end{array}$ Measurement Pattern

I. Set-Up Activities

Singing 105

43

31

2

9

13

Musical instruments

Arts and crafts

8

Preparing for arts and crafts

-

Playing with self-made art

projects

Exercising

3

6

1

3

Dancing

Bathing pool

Animal Care

Cultivation

6

Storytelling

Reading picture books

\section{1}

1

4

9

1

3 


\begin{tabular}{|c|c|c|c|c|c|c|c|}
\hline Geography & 4 & - & & & & & \\
\hline Adjusting a writing pressure & 2 & 2 & 2 & & & & \\
\hline Games & 9 & 7 & 7 & & 2 & & \\
\hline Pretend play & 6 & 5 & 4 & 3 & 1 & & \\
\hline Teacher's performance & 2 & - & & & & & \\
\hline Birthday celebration & 13 & 8 & 8 & 1 & & 2 & \\
\hline Practicing performances & 9 & 5 & 4 & 1 & 1 & 3 & \\
\hline Visiting other classrooms & 4 & - & & & & & \\
\hline $\begin{array}{l}\text { Measuring heights and } \\
\text { weights }\end{array}$ & 2 & 1 & 1 & & & & \\
\hline Evacuation drill & 1 & - & & & & & \\
\hline Instruction for facility use & 5 & 4 & 4 & & & 1 & \\
\hline Practicing standing in lines & 5 & 5 & 5 & & & 1 & \\
\hline \multirow[b]{3}{*}{ Types of activities } & 407 & 213 & 180 & 16 & 63 & 45 & 3 \\
\hline & & & \multicolumn{5}{|c|}{ Areas of mathematics } \\
\hline & activity & activity & Numbers & Arithmetic & $\begin{array}{l}\text { Space \& } \\
\text { Geometry }\end{array}$ & Measurement & Pattern \\
\hline \multicolumn{8}{|l|}{ II. Routine Activities } \\
\hline Attendance note & 17 & 14 & 14 & & & & \\
\hline Taking attendance & 53 & 44 & 44 & 19 & & & \\
\hline Class gathering & 77 & 25 & 23 & & 4 & 2 & \\
\hline Greetings & 66 & - & & & & & \\
\hline Introducing children on duty & 6 & 1 & 1 & & & & \\
\hline Date Confirmation & 18 & 18 & 18 & & & & \\
\hline $\begin{array}{l}\text { Checking future activity } \\
\text { schedules }\end{array}$ & 34 & 12 & 10 & & 2 & 1 & \\
\hline $\begin{array}{l}\text { Discussion about activity } \\
\text { content }\end{array}$ & 3 & 2 & 2 & 1 & 1 & & \\
\hline Thinking back on activities & 5 & 1 & 1 & & & & \\
\hline $\begin{array}{l}\text { Receiving letters or materials } \\
\text { for parents }\end{array}$ & 8 & 3 & 2 & & & 1 & \\
\hline Receiving awards & 5 & 1 & 1 & & & & \\
\hline $\begin{array}{l}\text { Teachers talk about living } \\
\text { habits }\end{array}$ & 13 & - & & & & & \\
\hline Health-care habits & 67 & 3 & 3 & & & & \\
\hline Clean-up & 69 & 19 & 8 & & 6 & 6 & \\
\hline Prayer/Meditation & 7 & - & & & & & \\
\hline Changing clothes & 24 & 5 & 4 & & & 1 & \\
\hline Changing location & 42 & 6 & 5 & & & 1 & \\
\hline Subtotal & 514 & 154 & 136 & 20 & 13 & 12 & 0 \\
\hline Total & 921 & 367 & 316 & 36 & 76 & 57 & 3 \\
\hline
\end{tabular}




\section{How Did Teachers Incorporate Mathematics into Preschool Activities?}

In the following subsections, I detail the mathematical support adopted by teachers in singing, arts and crafts, and taking attendance activities, during which mathematical components were most frequently observed.

Singing. Teachers frequently selected songs containing mathematical components in the lyrics. Of the 43 singing activities involving mathematics, 29 involved songs with mathematical lyrics containing one or more of the following areas of mathematics: numbers, space and geometry, and measurement. More than 25 types of mathematical songs were observed. When singing songs, teachers often encouraged the children to use their bodies to express numbers, sizes, or shapes described in the lyrics. Such behaviors were observed in 22 activities. In the following examples, the lyrics of two songs, one involving numbers and the other involving measurement, space and geometry, are presented. In both instances, the teacher encouraged the children to express the lyrics with their fingers and bodies.

Activity \#013-05 (Preschool O, 4-year-olds, OP1):The children sing a song with the teacher, responding to the numbers in the lyrics by holding up their fingers"(Holding up fingers) 1 and 5, we eat octopus dumplings.(Holding up fingers) 2 and 5, we eat pan-fried noodles.(Holding up fingers) 3 and 5, we eat cakes.(Holding up fingers) 4 and 5, we eat curry.(Holding up fingers) 5 and 5, we eat rice balls..."The fingers represent the objects described in the verse: one finger represents a stick; two fingers, chopsticks; three, a fork; four, a spoon; and five, a bowl. When they finish singing, one child says to the teacher "Let's sing faster!" The child then says "30 km!" (implying that the song should be sung at $30 \mathrm{~km} / \mathrm{hr}$ ). The teacher replies, "30 $\mathrm{km}$ is not so fast."

Activity \#051-04 (Preschool T, 3-year-olds, OP5): “A squirrel put a flu mask on its mouth. Put a small, small flu mask on its mouth. Ah, ah, ah, ahchoo! A crane put a flu mask on its mouth. Put a thin, thin flu mask on its mouth. Ah, ah, ah, ahchoo! A piggy put a flu mask on its mouth. Put a circle, circle flu mask on its mouth...." As the children and two teachers sing, one teacher holds paper masks of animals and fixes a properly shaped flu mask to her face. The other teacher indicates the body movements for the song.

Arts and crafts. Among the structured activities, mathematical activities were identified second-most frequently in arts and crafts (36 activities). Teachers prepared a variety of materials for arts and crafts, such as construction paper, ribbon, and empty milk cartons. They also instructed the children to create various projects, the theme of which was often animals or plants (e.g., crabs, snails, or grapes) or objects related to seasonal events in Japan, such as kites or playing cards in January, ogre masks in February, and Christmas tree ornaments or Santa Claus masks in December. Projects using origami paper (e.g., flowers or goldfish) or clay were also observed, as was drawing.

Teachers' mathematical support was observed most frequently when distributing the materials to the children (13 activities). Teachers frequently confirmed the number, size, or shape of the materials, inviting children to count or confirm the shape or size of the received materials independently or with the teacher. The following text illustrates an arts-and-crafts activity involving the number area.

Activity \# 141-02 (Preschool F, 4-year-olds, OP2): The teacher walks around the classroom distributing red strips of paper (crab feet) to each child. The teacher asks the children, "How many feet are each of you supposed to receive? Please count the number of crab feet that you have received." One boy reports to the teacher, "I have eight!" and confirms this by counting the feet one by one, "one, two, three...eight."... After all children have received their materials, the teacher addresses the whole class: "Well, let me ask you. Who has five feet? Who has six?" Only a few children hold up their hands. When the teacher asks, "Who has eight?" many children cheerfully raise their hands...

Teachers also frequently encouraged children to note the number, shape, and size of materials while explaining project construction (12 activities). The following examples demonstrate teacher involvement in space/geometry and measurement (first example), and space and geometry (second example).

Activity \#146-04 (Preschool H, 4-year-olds, OP2): The teacher stands in front of the class and explains how to make a goldfish with origami paper. The teacher points to the origami paper and asks, "What 
shape is this now?" The children answer, "Square!" The teacher replies, "Right, this is a square, and I will make this a triangle." The teacher folds the origami paper into a triangle. As she folds the large triangle in half, she requests, "Please make the big triangle into a small triangle, like this." She then unfolds the origami paper, and instructs the children to "pick one corner and put it on the cross, then crease the paper as if it has been ironed." Since many children have difficulty with this task, the teacher walks around the tables offering assistance.

Activity \#062-10 (Preschool D, 4-year-olds, OP5): The children construct ogre masks from a single newspaper page, by folding it into the shape of a helmet-style mask to be worn over the head. The teacher explains, "I folded the newspaper that you brought from your house into a square. Now, it is triangle." The teacher attaches a newspaper folded into a triangle on the black board. She explains how the paper should be further manipulated, using the newspaper on the blackboard as a demonstration. She instructs, "Place a triangle upward like a mountain. Then, hold the edge (base), not a side, and lift it (one angle of the triangle) up to the top." Some children say, "It became a square," while others say, "This is a diamond shape." Responding to the folding of the ogre mask, some children say, "This is same as (how we made) gold fish."

Taking attendance. Mathematical behaviors of both children and teachers were observed in 44 activities during the process of taking attendance. The teachers' mathematical support at this activity was observed most frequently when the teacher confirmed or asked the entire class to report the number of absent children on the day of observation (32 activities). In 14 attendance-taking activities, the children were also encouraged to calculate the total number of absent children, having counted the number of absent boys and girls separately. A typical example of mathematical support in attendance-taking, involving numbers and arithmetic, is given below.

Activity \#019-04 (Preschool H, 4-year-olds, OP1): At a morning gathering, the teacher called the name of each child. The teacher called out the names of the boys followed by those of the girls, and the children replied. When the name of an absent child was called, children responded collectively, "She is absent!"... When the teacher had finished calling the children's names, she asked the children, "How many boys (are absent) today?" The children replied, "Two!" She then asked, "How about girls?" The children collectively named the absent girl. The teacher repeated, "How many girls (are absent today)?" The children replied, "One!" The teacher then asked, "Then, how many boys and girls all together?" The children answered, "Three!" The teacher concluded with, "Right. Many friends have been absent recently. I hope there will be no more absent friends."

\section{Are Embedded Math Activities Effective in Facilitating Children's Mathematical Learning?}

The above observational data suggest that Japanese preschool teachers rarely teach mathematics systematically. Rather, they frequently introduce mathematics, especially numbers, as embedded components of other teacher-initiated activities, such as singing songs, creating an art project, or taking attendance. Are these embedded mathematical support effective in facilitating children's mathematical learning?

To examine whether the amount of mathematical support provided by Japanese preschool teachers had different effects on the children's mathematical competence, mathematical performance of children attending classrooms with different levels of teacher-provided mathematical support was compared (Sakakibara, 2006). 130 children (61 3-year-olds and 69 4-year-olds) from the 14 observed classrooms took Child Math Assessment (CMA) (Starkey \& Klein, 2008). The version of CMA used in this study comprised 17 tasks covering five areas of informal mathematics; numbers, arithmetic, space and geometry, measurement, and patterns. The CMA was administered twice to each child, at the beginning of the academic year (MayJuly) and toward the end (Jan-Mar). (The school year goes from April to March in Japan.) The result showed an effect of the teachers' support on both 3- and 4-year-old children's number performance: the children who were given a high amount of mathematical support by their teachers showed better number competence than those who received moderate or less support, although no such effect on overall math competence was found. 


\section{Why do Japanese Preschool Teachers Embed Mathematics Frequently, When They Have No Intention to Support Children's Mathematical Learning?}

As described above, Japanese preschool teachers effectively facilitate children's mathematics learning, without relying on systematic math instruction. However, despite offering frequent and active mathematical support, Japanese preschool teachers do not intentionally support children's mathematical learning (Sakakibara \& Hatano, 2004). Many teachers believe that mathematics learning is not important for preschool children. Why do Japanese teachers incorporate embedded mathematical components so frequently into their preschool activities, when they are unwilling to teach mathematics?

Mathematical activities practiced in certain cultures reflect the values and beliefs shared by the mature members of the culture as regards children's mathematical development (Rogoff, 2003). The frequent incorporation of mathematics into Japanese preschool activities may echo Japanese cultural values, which include a high regard for mathematical competence (Hatano \& Inagaki, 1999). Although mathematics teaching is not the primary goal of Japanese preschool teachers, as mature members of Japanese culture, helping children learn mathematics may still be an unconscious secondary objective of the teachers. For this reason, Japanese preschool teachers frequently use mathematical components in constructing preschool activities and in attracting children's attention to, and interest in, teacher-initiated activities, which resulted in developing an abundant repertory of methods for embedding math components in various activities.

\section{Summary and Implication - What Makes Embedded Mathematical Support Effective?}

In this article, I have introduced studies that illustrate how Japanese preschool teachers frequently embed mathematical components into everyday activities. Such embedding facilitates mathematical learning by young children. Since attitudes towards children's mathematical learning and education styles differ between cultures, simply implementing support strategies of one culture to another could be ineffective. However, it is beneficial to know the cultural variations, as they could be an alternative and effective strategy when culturally appropriate modification is made. Mathematical embedding, for example, could be an effective strategy in many cultures to facilitate young children's mathematical learning. Based on observational studies of Japanese preschools, I emphasize two important factors for successful embedding of mathematical activities.

First, the teacher must be sensitive to the children's current state of mathematical development. To attract children's interest in embedded mathematics and facilitate their mathematical learning, teachers must adopt appropriate levels of mathematics with appropriate support. In our alternative free play study (Sakakibara, Hatano \& Inagaki, 2001), when teachers participated in origami projects and presented the children with slightly more advanced objects than the children had themselves constructed, the mathematical activity of the children was expanded and stimulated. This suggests that, by constantly assessing the children's zone of proximal development (Vygotsky, 1978) of mathematics in action, teachers can embed appropriately challenging mathematical tasks into activities.

The other important factor appears to be teachers' flexibility and responsiveness when introducing mathematics to various activities. Studies of young children's free play suggest that young children, regardless of culture, are highly interested in mathematics. During naturalistic observations of a US daycare center, Ginsburg et al. (1999) found that children frequently engage in mathematical activities, devoting approximately $45 \%$ of their playtime to such activities. Another intercultural study revealed that Chinese children engage in more pattern and shape activities than US children, although the complexity of mathematical activities is the same in both cultures (Ginsberg, Lin, Ness, \& Seo, 2003). Children develop mathematical interests in many contexts during preschool activities. The more flexible the teachers embed mathematics in various activities responding to children's spontaneous interests, the more frequently and intriguingly the children engage in mathematics.

As mentioned above, the mathematical knowledge acquired by young children lays a foundation for higher mathematical learning. This has been confirmed, not only in lower grades but also up to middle grades and beyond. To support children's mathematics learning at school, appropriate pre-school mathematics education is mandatory. However, systematic teaching of early mathematics is one of several 
ways of providing this support. Embedded mathematical activities present as an alternative and potentially effective way to facilitate young children's mathematics learning. Kulm (2013) suggests three assessment strategies that could be adopted in mathematics classrooms: performance assessment, informal classroom assessment, and classroom discourse and questioning. These strategies have certain commonalities with preschool assessment strategies by which mathematics can be appropriately embedded into activities. Comparing the required assessment strategies in preschool and elementary school mathematics teaching might elucidate the relevant teaching skills, leading to enhanced and consistent support for children's mathematics learning at preschool and throughout elementary school.

\section{References}

Duncan, G. J., Dowsett, C. J., Claessens, A., Magnuson, K., Huston, A. C., Klebanov, P., Duckworth, K. (2007). School readiness and later achievement. Developmental Psychology, 43(6), 1428-1446.

Ginsburg, H. P., Choi, Y. E., Lopez, L. S., Netley, R., \& Chi, C. Y. (1997). Happy birthday to you: The early mathematical thinking of Asian, South American, and U.S. children. In T. Nunes, \& P. Bryant (Eds.), Learning and teaching mathematics: An international perspective (pp. 1-45). East Sussex, England: Erlbaum/Taylor \& Francis.

Ginsburg, H. P., Inoue, N., \& Seo, K. H. (1999). Young children doing mathematics: Observations of everyday activities. In J. V. Copley (Ed.), Mathematics in the early years (pp. 88-99). Washington: National Association for the Education of Young Children.

Ginsburg, H. P., Lin, C., Ness, D., \& Seo, K. H. (2003). Young American and Chinese children's everyday mathematical activity. Mathematical Thinking and Learning, 5(4), 235-258.

Hatano, G., \& Inagaki, K. (1999). Early childhood mathematics in Japan. In J. V. Copley (Ed.), Mathematics in the early years (pp. 219-226). Reston, VA: The National Council of Teachers of Mathematics.

Jordan, N. C., Kaplan, D., Ramineni, C., \& Locuniak, M. N. (2009). Early math matters: Kindergarten number competence and later mathematics outcomes. Developmental Psychology, 45(3), 850-867.

Jordan, N. C., \& Levine, S. C. (2009). Socioeconomic variation, number competence, and mathematics learning difficulties in young children. Developmental Disabilities Research Reviews, 15, 60-68.

Kulm, G. (2013). Back to the future: reclaiming effective mathematics assessment strategies. Middle Grades Research Journal

Krajewski, K. \& Schneider, W. (2009). Early development of quantity to number-word linkage as a precursor of mathematical school achievement and mathematical difficulties: findings from a four-year longitudinal study. Learning and Instruction, 19, 513-526.

Mayer, R., Valerie, S., \& Tajika, H. (1995). A comparison of how textbooks teach mathematical problem solving in Japan and the United States. American Educational Research Journal, 32(2), 443-460.

Ministry of Education, Culture, Sports, Science and Technology (2008). Course of study for Kindergarten. Retrieved from

http://www.mext.go.jp/a_menu/shotou/new-cs/youryou/eiyaku/1298368.htm

Mullis, I. V. S., Martin, M. O., Foy, P. \& Arora, A. (2012). TIMSS 2011 International results in mathematics. Chestnut Hill, MA: TIMSS \& PIRLS International Study Center, Boston College.

Perry, M., \& VanderStoep, S. W., \& Yu, S. L. (1993). Asking questions in first-grade mathematics classes: Potential influences on mathematical thought. Journal of Educational Psychology, 85(1), 31-40.

Rogoff, B. (2003). The cultural nature of human development. New York: Oxford University Press

Sakakibara, T. (2006). The role of Japanese preschool teachers' support in young children's mathematical development. The Japanese Journal of Developmental Psychology, 17(1), 50-61. [in Japanese]

Sakakibara, T. \& Hatano, G. (2004, September). Mathematical instruction in preschool activity: Preschool teachers' belief about young children's mathematical development. Paper presented at the $68^{\text {th }}$ Annual Convention of Japanese Psychological Association at Kansai University, Osaka, Japan. [in Japanese]

Sakakibara, T., Hatano, G., \& Inagaki, K. (2001). The development of numerical competence among Japanese young children. Research Bulletin of Graduate School of Social Sciences, Keio University, 52, 1-5.

Stakey, P., \& Klein, A. (2008). Sociocultural influences of young children's mathematical knowledge. In O. N. Saracho \& B. Spodek (Eds.), Contemporary Perspectives on Mathematics in Early Childhood Education (pp. 253-276). Charlotte, NC: Information Age Publishing. 
Stigler, J. W., \& Hiebert, J. (1999). The Teaching Gap. New York: The Free Press.

Stevenson, H. W., Lee, S-Y., \& Stigler, J. W. (1986). Mathematics achievement of Chinese, Japanese, and American children. Science, 231, 693-699.

Stevenson, H. W., \& Stigler, J. W. (1992). The learning gap. New York: Simon \& Schuster.

Tobin, J.D., Wu, D., \&Davidson, D. (1989). Preschool in Three Cultures: Japan, China, and the United States. New Haven, CT: Yale University Press.

Vygotsky, L. S. (1978). Mind in society: The development of higher psychological processes. Cambridge, MA: Harvard University Press. 